\title{
Gerakan Keluarga Sadar Obat pada Kelompok Darma Wanita dengan Pendekatan Belajar Aktif
}

\author{
Pande Ayu Naya Kasih Permatananda*, Anak Agung Sri Agung Aryastuti, Putu Nita Cahyawati \\ Departemen Farmakologi dan Farmasi, Fakultas Kedokteran dan IImu Kesehatan, Denpasar
}

Submisi: 31 Desember 2018 ; Revisi: 16 Maret 2020; Penerimaan: 18 Maret 2020

Kata Kunci:
Ibu rumah
tangga
Obat keluarga
Pemberdayaan
$\quad$ keluarga
Pengabdian
$\quad$ masyarakat

Keywords:

Community services

Family

empowerment

Family medicine

Housewife

\begin{abstract}
Abstrak Untuk mengatasi maraknya praktik swamedikasi atau melakukan pengobatan sendiri yang tidak benar di masyarakat diperlukan upaya peningkatan pemahaman penggunaan obat-obatan yang rasional di masyarakat. Kegiatan pengabdian masyarakat ini menyasar ibu-ibu rumah tangga yang tergabung dalam kelompok Darma Wanita Kota Denpasar dan bertujuan untuk meningkatkan pemahaman mereka dalam praktik swamedikasi pada keluarga. Metode belajar aktif digunakan sebagai strategi dalam penyampaian materi kepada peserta. Evaluasi kegiatan dilakukan melalui observasi selama kegiatan serta penilaian pre-test dan post-test. Peserta mengikuti seluruh kegiatan dengan aktif. Dari dua puluh pertanyaan yang dibagi dalam empat topik swamedikasi diperoleh nilai rata-rata pre-test 6,65; 6,85; 7,11; dan 6,11 serta nilai rata-rata post-test 8,$57 ; 8,85 ; 8,42$; dan 8,5 . Dengan demikian, terdapat peningkatan nilai post-test dibandingkan pre-test (nilai $p<0,05$ ). Pemberian materi dengan metode belajar aktif mampu meningkatkan pengetahuan kelompok Darma Wanita Kota Denpasar dalam mewujudkan swamedikasi yang rasional. Para peserta diharapkan dapat menjadi pelopor gerakan keluarga sadar obat bagi keluarganya.

Abstract In order to overcome the widespread practice of improper selfmedication in our community, an effort to increase the understanding regarding the rational use of medicines is needed. This community service activity targets housewives who are members of Kelompok Dharma Wanita Denpasar to improve the understanding of mothers in applying self-medication practices in the family. Active learning methods are used as a strategy to help deliver learning material to participants. We made observations during the process of learning and pretest-posttest scoring as evaluation methods. Participants actively took parts in all activities and Out of 20 questions that were divided into 4 topics of self medication, we got mean of pretest score from topic 1 (get), topic 2 (use), topic 3 (save), and topic 4 (throw away) as follow: 6,65; 6,85; 7,11; 6,11, while mean of posttest score for those topics were 8,$57 ; 8,85 ; 8,42 ; 8,5$. Therefore, there was an increase in the posttest score compared to the pretest (p-value $<0.05)$.. The active learning process can increase the knowledge of participants in realizing rational self-medication. The participants are expected to be the pioneers of family awareness of drug movement in their families.
\end{abstract}

\section{PENDAHULUAN}

Di tengah kemajuan teknologi informasi, masyarakat menjadi semakin maju dan semakin peduli terhadap dirinya sendiri (self care) dalam segala aspek, baik kesehatan, sosioekonomi, lingkungan, nutrisi, maupun
Gaya hidup. Dalam bidang kesehatan, self care diartikan sebagai upaya yang dilakukan oleh seseorang terhadap dirinya untuk membangun dan memelihara kesehatannya, termasuk mencegah dan mengobati penyakit (Galato et al., 2009). Dalam hal penanggulangan penyakit, beberapa upaya dilakukan

ISSN 2460-9447 (print), ISSN 2541-5883 (online)

${ }^{*}$ Corresponding author : Pande Ayu Naya Kasih Permatananda

Departemen Farmakologi dan Farmasi, Fakultas Kedokteran dan Ilmu Kesehatan, Jl. Teropong no 24 Denpasar, Indonesia 80234

Email:nayakasih@gmail.com 
oleh masyarakat, yakni memeriksakan diri ke dokter atau memutuskan untuk membeli obat sendiri ke apotek. Pengobatan sendiri atau swamedikasi (self medication) merupakan upaya yang paling banyak dilakukan oleh masyarakat untuk mengatasi keluhan atau gejala penyakit sebelum mereka memutuskan untuk mencari pertolongan ke fasilitas pelayanan kesehatan atau tenaga kesehatan. World Health Organization (WHO) pada 1998 mendefinisikan swamedikasi sebagai praktik atau upaya yang dilakukan seseorang untuk mengatasi gejala atau keluhan ringan yang diakuinya dengan obat-obatan. Apabila dilakukan dengan benar, praktik swamedikasi sangat bermanfaat bagi kesehatan dan diakui oleh WHO sebagai bagian dari self-care (WHO, 1998; Galato et al., 2009). Lebih dari 60\% masyarakat Indonesia mempraktikkan self-medication dan lebih dari $80 \%$ di antara mereka mengandalkan obat modern. Hasil Riset Kesehatan Dasar yang dilakukan oleh Kementerian Kesehatan Indonesia (Kemenkes) pada tahun 2013 menunjukkan bahwa 35,2\% masyarakat Indonesia menyimpan obat di rumah, baik yang diperoleh dari resep dokter maupun dibeli sendiri secara bebas, dan $27,8 \%$ di antaranya adalah antibiotik (Kemenkes, 2013).

Masyarakat menilai bahwa swamedikasi dapat meminimalkan penggunaan obat-obat yang seharusnya dapat digunakan untuk masalah kesehatan serius dan menurunkan biaya pengobatan di layanan-layanan kesehatan. Namun, praktek swamedikasi juga dapat membahayakan kesehatan apabila obat-obatan yang didapat tidak digunakan sesuai aturan, terdapat kesalahan informasi penggunaan obat, serta terjadi reaksi obat yang tidak diinginkan. Kesalahan pemilihan obat akibat kesalahan diagnosis juga sering terjadi akibat pemilihan obat yang pada umumnya dipengaruhi oleh pengalaman di masa lalu dan lingkungan sosial (Permatananda et al., 2018; Aswad et al., 2019).

Untuk pengobatan penyakit dengan keluhan ringan, praktik swamedikasi sangat membantu masyarakat dan membantu pemerintah terutama dalam pemeliharaan kesehatan secara nasional. Keluhan ringan didefinisikan sebagai keluhan atau gejala penyakit yang berlangsung hanya sementara dan tidak membahayakan. Dengan adanya praktik swamedikasi untuk keluhan-keluhan ringan, institusi kesehatan dapat lebih fokus pada masalah kesehatan yang lebih serius (Volmer et al., 2007). Data yang dikumpulkan di Amerika Serikat menunjukkan bahwa 100-150 juta konsultasi yang dilakukan dengan dokter umum dalam setahun sesungguhnya merupakan keluhan ringan yang dapat ditangani sendiri (Whittington, 2001).

Pemberian jaminan kesehatan gratis kepada penduduk atau warga di suatu negara tidak serta merta menurunkan praktik swamedikasi, misalnya di Brazil yang ternyata $35 \%$ penjualan obat dilakukan secara swamedikasi (Galato et al., 2009). Praktik swamedikasi yang tidak tepat dapat menyebabkan berbagai permasalahan kesehatan, misalnya tidak tercapainya efek pengobatan, timbulnya efek samping, serta munculnya penyakit baru (Permatananda et al., 2018). Beberapa kasus kesehatan serius juga dapat terjadi, yaitu resistansi bakteri, ketergantungan terhadap obat, pendarahan saluran cerna, bahkan peningkatan risiko neoplasma akibat penyalahgunaan obat-obatan tanpa berkonsultasi dengan dokter. Kasus keracunan pada manusia paling sering disebabkan oleh obat-obatan. Dua puluh enam persen kasus keracunan pada tahun 2005 terjadi akibat penggunaan obat-obatan dan 590 kasus di antaranya terjadi akibat perilaku swamedikasi di masyarakat yang tidak tepat (Galato et al., 2009). Perilaku swamedikasi yang tidak tepat dapat disebabkan oleh terbatasnya pengetahuan masyarakat, kurangnya informasi dari tenaga kesehatan, dan kurangnya kesadaran serta kemampuan masyarakat untuk mencari informasi melalui sumber informasi yang relevan dan tepat.

Kota Denpasar merupakan ibu kota Provinsi Bali yang terbagi menjadi empat kecamatan. Denpasar Selatan merupakan kecamatan dengan jumlah penduduk terbanyak. Kota Denpasar memiliki komposisi masyarakat yang majemuk dengan tingkat pendidikan yang beragam (Badan Pusat Statistik [BPS], 2018). Sebuah penelitian di Kota Denpasar pada 2014 menunjukkan bahwa $40 \%$ responden memiliki tingkat pengetahuan yang baik terkait obat-obatan dan swamedikasi. Akan tetapi, sebagian besar responden tidak mampu menjawab pertanyaan yang tepat terkait penggolongan obat swamedikasi, tidak mengetahui cara penyimpanan obat, dan penanganan obat yang rusak atau kadaluarsa (Antari et al., 2014). Dengan demikian, masyarakat memerlukan informasi yang jelas, benar, dan dapat dipercaya agar dapat melakukan swamedikasi yang rasional.

Swamedikasi hendaknya hanya dilakukan pada penyakit ringan yang bertujuan untuk mengurangi gejala. Selain itu, obat yang diperoleh tanpa resep dokter harus tetap sesuai dengan ketentuan perundangundangan yang berlaku. Pemberian edukasi terkait swamedikasi kepada ibu-ibu rumah tangga dianggap penting mengingat ibu-ibu merupakan garda terdepan dalam penyelenggaraan kesehatan di keluarganya. Pemahaman tentang swamedikasi sangat penting dimiliki oleh para ibu untuk menunjang kesehatan keluarga. Kami melaksanakan kegiatan pengabdian masyarakat berupa gerakan keluarga sadar obat yang bertujuan untuk memberikan edukasi kepada masyarakat agar dapat memilih dan menggunakan obat dengan benar pada saat melakukan swamedikasi. Melalui kegiatan tersebut, masyarakat terutama para 
ibu diharapkan dapat lebih aktif dalam mencari informasi mengenai obat-obatan sehingga obat digunakan dengan benar dan tujuan swamedikasi tercapai secara optimal.

Pengabdian masyarakat ini menyasar ibu-ibu rumah tangga anggota kelompok Darma Wanita Kota Denpasar yang merupakan pelopor kesehatan dalam keluarga dan banyak melakukan praktik swamedikasi di rumah. Fasilitas kesehatan yang jauh dan keengganan untuk mengantre karena keterbatasan waktu mengakibatkan banyak ibu rumah tangga membeli obat untuk dirinya dan keluarga tanpa pergi ke fasilitas layanan kesehatan. Selain itu, banyaknya apotek di Kota Denpasar semakin memudahkan masyarakat untuk membeli obat dan membuat ibu rumah tangga malas untuk berkonsultasi dengan dokter. Mencari informasi terkait keluhan secara mandiri di internet atau dari penjaga apotek dinilai lebih praktis daripada harus mengantre hanya untuk bertemu dokter. Selama gejala atau keluhan yang dialami masih tergolong ringan, membeli obat di apotek atau di warung dianggap lebih mudah dan cepat. Obat-obatan yang biasa dibeli tanpa resep dokter antara lain obat untuk keluhan batuk pilek, obat penurun panas, obat untuk keluhan gatal, obat anti jamur, obat tetes mata, obat tetes telinga, dan antibiotik yang sering ditawarkan oleh penjaga apotek.

Di rumah, banyak ibu rumah tangga yang tidak memiliki tempat khusus untuk menyimpan obat. Mereka biasanya membeli obat seperlunya sehingga merasa tidak perlu untuk menyimpan obat secara khusus. Obat yang tersisa biasanya disimpan dalam lemari. Ada beberapa obat yang menurut pengetahuan ibu rumah tangga sebaiknya disimpan di lemari es setelah dibuka agar tidak tercemar kuman. Ibu rumah tangga juga mengaku sangat jarang membaca kemasan atau brosur obat, namun mereka cukup mengerti tentang masa kadaluarsa obat. Obat yang sudah kadaluarsa tidak bisa dipakai dan harus dibuang ke tempat sampah. Dari hasil dialog dengan para ibu dari kelompok Darma Wanita Kota Denpasar diketahui bahwa terdapat banyak kesalahan persepsi terkait pembelian, penggunaan, penyimpanan, dan pembuangan obat-obatan. Karena permasalahan tersebut, tim pengabdi memutuskan untuk memberikan edukasi dalam bentuk pembelajaran aktif terkait penggolongan, penggunaan, penyimpanan, dan pembuangan obat. Metode belajar aktif dipilih untuk mempermudah pemahaman dan aplikasinya dalam kehidupan sehari-hari.

\section{METODE PELAKSANAAN}

Dua pokok kegiatan yang dilakukan dalam pengabdian masyarakat ini adalah pemberian materi dan pendampingan keluarga. Materi yang diberikan adalah penggolongan obat, penggunaan obat, penyimpanan obat, dan pembuangan obat yang rusak atau dikenal dengan jargon Dagusibu (Dapat, Gunakan, Simpan, Buang). Pemaparan materi diselingi dengan simulasi langsung teknik pemakaian obat-obatan yang biasa dilakukan di rumah. Setelah pemberian materi, peserta kemudian dibagi menjadi dua kelompok. Masingmasing kelompok berdiskusi bersama satu orang narasumber atau pendamping. Pada sesi diskusi tersebut, pendamping atau narasumber membagikan paket obat-obatan. Peserta belajar mengidentifikasi obat (nama dagang, nama bahan aktif, dosis atau kekuatan bahan aktif, bahan aktif utama, dan tambahan pada obat kombinasi). Peserta juga berlatih untuk mencari informasi tentang obat dari kemasan dengan meneliti setiap tulisan yang ada pada produk. Setelah diskusi kelompok, kemudian dilakukan pemilihan tiga orang ibu yang mendapatkan pendampingan pemasangan kotak pertolongan pertama pada kecelakaan $(\mathrm{P} 3 \mathrm{~K})$ dan penggunaan obat-obat P3K di rumah.

Metode yang digunakan dalam kegiatan pengabdian masyarakat ini adalah metode belajar aktif. Metode belajar aktif merupakan adaptasi dari metode community interest-based approach atau cara belajar insan aktif (CBIA), yaitu metode penyampaian informasi perihal obat dengan melibatkan subjek secara aktif untuk mendengar, melihat, menulis, dan melakukan evaluasi mengenai pengenalan jenis obat dan bahan aktif, termasuk informasi tentang indikasi, kontraindikasi, dan efek samping (Widayati et al., 2008). Metode CBIA dapat meningkatkan pengetahuan siswa di Kota Metro tentang obat common cold sebanyak 62\% (Noerdianingsih, 2014).

Sarana dan prasarana yang digunakan terdiri atas beberapa jenis sediaan obat dalam bentuk cairan yaitu sirup, eliksir, dan obat tetes, serta obat luar berupa krim dan salep (Lampiran 1). Selain itu, disertakan pula brosur dari pabrik sebagai informasi produk (Lampiran 2) serta beberapa sediaan tablet dalam kemasan, baik obat bebas maupun obat keras. Selain paket obat, juga disiapkan lembar pre-test dan post-test sebagai bahan evaluasi kegiatan.

Narasumber yang dipilih merupakan tiga dosen dari Departemen Farmakologi dan Farmasi, Fakultas Kedokteran, Universitas Warmadewa, Denpasar Ketiga narasumber tersebut juga berfungsi sebagai pendamping, baik pendamping diskusi maupun pendamping keluarga. Pemahaman narasumber terkait materi sudah diseragamkan agar tidak terjadi perbedaan penyampaian informasi kepada peserta. 
Kegiatan pengabdian masyarakat ini terdiri atas pemberian materi oleh narasumber utama yang kemudian dilanjutkan dengan simulasi, tanya jawab, dan diskusi kelompok. Materi yang disampaikan oleh narasumber meliputi empat topik Dagusibu (Dapat, Gunakan, Simpan, dan Buang). Materi "Dapat" meliputi cara memperoleh obat dengan benar serta mengetahui jenis-jenis obat, baik yang dapat dibeli secara mandiri maupun yang harus melalui resep dokter. Materi “Gunakan” meliputi memahami manfaat brosur pada kemasan serta tata cara aplikasi obat tetes mata, tetes telinga, dan aneka sediaan obat cair. Materi "Simpan" terdiri atas cara menyimpan obat dengan benar dan memahami pentingnya memiliki media penyimpanan khusus untuk obat serta selalu memperhatikan waktu kadaluarsa obat. Materi "Buang" terdiri atas bagaimana mengetahui ciri-ciri obat yang sudah rusak atau tidak layak dikonsumsi serta cara membuangnya agar tidak membahayakan lingkungan.

Pada akhir sesi, tiga peserta yang aktif saat penyampaian materi dan aktif berdiskusi mendapatkan kotak P3K yang dapat digunakan sebagai media penyimpanan obat di rumah. Evaluasi dilakukan dengan melakukan pre-test dan post-test sebelum pemberian materi dan setelah diskusi kelompok dilakukan. Keberhasilan kegiatan juga diukur dengan melihat antusiasme peserta dalam mengikuti setiap kegiatan.

Analisis data dilakukan secara kualitatif dan kuantitatif. Hasil kegiatan yang berupa gambaran pelaksanaan kegiatan disajikan secara naratif. Data yang terkumpul, seperti karakteristik peserta kegiatan ditampilkan secara deskriptif dan dalam bentuk tabel persentase. Evaluasi kegiatan, yaitu hasil pre-test dan post-test disajikan dalam bentuk diagram batang dengan melihat perbedaan rata-rata nilai pre-test dan post-test hasil uji T. Perbedaan dinyatakan bermakna apabila nilai $\mathrm{p}<0,05)$. Hasil analisis juga dibandingkan dengan hasil-hasil kajian sebelumnya.

\section{HASIL DAN PEMBAHASAN}

Peserta kegiatan berjumlah 28 orang yang merupakan anggota kelompok Darma Wanita Kota Denpasar. Karakteristik peserta yang meliputi umur, pekerjaan, pendidikan, jumlah anggota keluarga, serta kepemilikan Jaminan Kesehatan Nasional (JKN) disajikan pada Tabel 1.
Tabel 1. Karakteristik peserta pengabdian masyarakat

\begin{tabular}{|c|c|}
\hline Karakteristik & n $(\%)$ \\
\hline \multicolumn{2}{|l|}{ Umur } \\
\hline$\leq 30$ tahun & $13(46,4)$ \\
\hline$>30$ tahun & $15(53,6)$ \\
\hline \multicolumn{2}{|l|}{ Pekerjaan } \\
\hline Bekerja & $18(64,2)$ \\
\hline Tidak bekerja & $10(35,8)$ \\
\hline \multicolumn{2}{|l|}{ Pendidikan } \\
\hline Di bawah SMA & $10(35,8)$ \\
\hline Setara atau lebih tinggi dari SMA & $18(64,2)$ \\
\hline \multicolumn{2}{|l|}{ Jumlah anggota keluarga dalam $\mathrm{KK}^{*}$} \\
\hline$\leq 4$ orang & $12(42,8)$ \\
\hline$>4$ orang & $16(57,2)$ \\
\hline \multicolumn{2}{|l|}{ Memiliki JKN** } \\
\hline Ya & $22(78,6)$ \\
\hline Tidak & $6(21,4)$ \\
\hline
\end{tabular}

Ibu rumah tangga menjadi sasaran dalam kegiatan pengabdian masyarakat ini karena mereka dianggap memiliki peranan paling penting dalam penentuan derajat kesehatan dan kualitas sumber daya dalam keluarga. Perempuan dianggap lebih peka dan memegang peran penting dalam pengambilan keputusan terkait kesehatan dalam keluarga, termasuk memilih obat yang akan digunakan ketika salah satu anggota keluarga mengalami gangguan kesehatan (Zoraida, 2012). Berdasarkan hasil penelitian sebelumnya diketahui bahwa prevalensi ibu rumah tangga yang menggunakan obat bebas atau obat terbatas dalam upaya pengobatan sendiri sebesar $74,4 \%$ dengan rincian obat bebas $80,9 \%$ dan obat terbatas 19,1\% (Handayani, 2018). Sebagian besar peserta berusia lebih dari 30 tahun dan aktif bekerja. Tingkat pendidikan peserta sebagian besar setara dengan sekolah menengah atas (SMA) atau lebih. Hanya ada satu peserta yang tidak mampu membaca dan menulis karena tidak menamatkan pendidikan dasar sehingga pengisian pre-test dan post-test didampingi oleh narasumber.

Kepemilikan Jaminan Kesehatan Nasional (JKN) merupakan salah satu faktor yang memengaruhi praktik swamedikasi masyarakat. Masyarakat yang memiliki JKN cenderung tidak melakukan praktik swamedikasi (Galato et al., 2009). Sebagian besar peserta kegiatan memiliki JKN meskipun memiliki jumlah anggota keluarga banyak (lebih dari empat orang). Berdasarkan data Badan Kependudukan dan Keluarga Berencana Nasional (BKKBN), jumlah rata-rata anggota keluarga dalam satu keluarga di Kota Denpasar adalah empat 
orang (BKKBN, 2011). Jumlah anggota keluarga yang banyak menjadi alasan terbanyak masyarakat merasa keberatan atau menolak untuk mengikuti JKN. Jumlah anggota keluarga berdampak pada persepsi mengenai kewajiban mendaftarkan seluruh anggota keluarganya dalam JKN. Hal tersebut terjadi karena adanya kewajiban untuk membayar iuran sesuai dengan jumlah anggota keluarga yang didaftarkan sehingga semakin banyak jumlah anggota keluarga semakin besar jumlah iuran yang harus dibayarkan (Wisudarma et al., 2015).

Pada proses penggalian informasi awal terkait swamedikasi diketahui bahwa semua anggota kelompok Darma Wanita Kota Denpasar pernah melakukan swamedikasi, baik untuk dirinya sendiri maupun untuk anggota keluarganya di rumah. Penelitian yang dilakukan di Sri Lanka oleh Silva et al. (2017) menunjukkan bahwa persentase tertinggi perilaku swamedikasi oleh ibu rumah tangga dilakukan oleh ibu-ibu dengan tingkat pendidikan tinggi dan tidak bekerja. Studi tersebut juga menyebutkan bahwa swamedikasi cenderung meningkat seiring usia anak dan terdapat korelasi bermakna antara jumlah anggota keluarga dengan perilaku swamedikasi, yaitu semakin banyak jumlah anggota keluarga maka perilaku swamedikasi juga meningkat (Silva et al., 2017).

Dua hal yang menjadi acuan dalam mengevaluasi keberhasilan kegiatan adalah hasil observasi langsung pada peserta saat kegiatan dan hasil pre-test dan posttest. Secara umum, antusiasme kelompok Darma Wanita Kota Denpasar dalam mengikuti kegiatan cukup baik. Para peserta hadir tepat waktu dan semua bersedia mengikuti seluruh kegiatan dengan baik, mulai dari pre-test, pemberian materi, diskusi kelompok, hingga post-test. Seluruh peserta terlibat aktif dalam rangkaian proses belajar aktif pada sesi pemberian materi. Beberapa pertanyaan yang disampaikan peserta, antara lain terkait hipertensi dan penggunaan obat hipertensi secara berkelanjutan, penanganan anak yang sering mengalami epistaksis, pengobatan asma pada anak dan tata cara melakukan nebulisasi, serta tata cara penyimpanan obat di lemari es. Kotak P3K diberikan kepada peserta yang terpilih kemudian dilakukan pendampingan pemasangan kotak $\mathrm{P} 3 \mathrm{~K}$ di rumah mereka masing-masing.

Pre-test dan post-test masing-masing terdiri atas 20 pertanyaan yang terbagi dalam 4 topik swamedikasi (Tabel 2). Soal pre-test dan post-test berupa soal pilihan ganda yang berjenis sama untuk memudahkan evaluasi peningkatan pengetahuan peserta setelah pemberian materi. Nilai rata-rata pre-test topik 1 (Dapat), topik 2 (Gunakan), topik 3 (Simpan), dan topik 4 (Buang), yaitu 6,$65 ; 6,85 ; 7,11$; dan 6,11 , sedangkan nilai ratarata post-test untuk setiap topik secara berurutan adalah 8,$57 ; 8,85 ; 8,42 ;$ dan 8,5 . Terdapat peningkatan bermakna nilai rata-rata post-test dibandingkan nilai rata-rata pre-test untuk setiap topik ( $p<0,05$, Gambar $1)$.

Tabel 2. Empat topik swamedikasi yang menjadi pertanyaan dalam pre-test dan post-test

\begin{tabular}{|c|c|c|}
\hline No & Topik pertanyaan & $\begin{array}{l}\text { Jumlah } \\
\text { pertanyaan }\end{array}$ \\
\hline \multirow[t]{3}{*}{1} & Dapat & \\
\hline & $\begin{array}{l}\text { a. mengetahui cara } \\
\text { mendapatkan obat-obatan } \\
\text { yang benar }\end{array}$ & 5 \\
\hline & $\begin{array}{l}\text { b. mengetahui penggolongan } \\
\text { obat bebas dan terbatas }\end{array}$ & \\
\hline \multirow[t]{2}{*}{2} & Gunakan & \\
\hline & $\begin{array}{l}\text { mengetahui cara menggunakan } \\
\text { obat-obatan dengan benar, } \\
\text { termasuk bentuk obat sediaan } \\
\text { obat khusus }\end{array}$ & 5 \\
\hline \multirow[t]{2}{*}{3} & Simpan & \\
\hline & $\begin{array}{l}\text { mengetahui cara menyimpan } \\
\text { obat di rumah }\end{array}$ & 5 \\
\hline \multirow[t]{3}{*}{4} & Buang & \\
\hline & $\begin{array}{l}\text { a. mengetahui tata cara } \\
\text { pembuangan obat }\end{array}$ & 5 \\
\hline & $\begin{array}{l}\text { b. mengetahui ciri obat } \\
\text { kadaluarsa atau rusak }\end{array}$ & \\
\hline
\end{tabular}

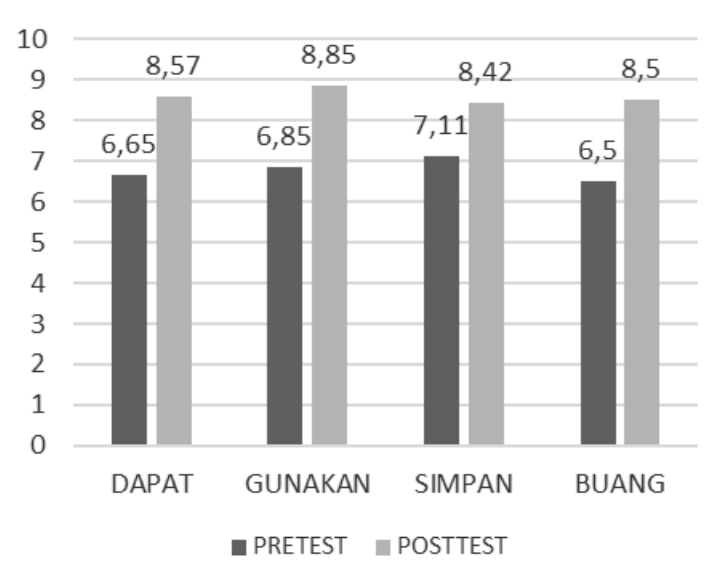

Gambar 1. Perbandingan nilai rata-rata pre-testdan post-test

Kegiatan pengabdian masyarakat ini menggunakan metode pendekatan belajar aktif yang banyak digunakan sebagai teknik pemberian materi terkait pengobatan kepada masyarakat yang bertujuan tidak hanya untuk meningkatkan pengetahuan, namun juga untuk memperteguh keyakinan serta memperbaiki perilaku. Metode belajar aktif merupakan adaptasi dari metode community interest-based approach atau CBIA (Widayati et al., 2008). Metode CBIA berbeda dengan penyuluhan dan edukasi pada umumnya. Metode ini dinilai lebih efektif untuk meningkatkan pengetahuan dan pemahaman daripada metode ceramah atau tanya jawab. Dalam metode tersebut peserta dibagi ke dalam 
beberapa kelompok kecil dan masing-masing kelompok ditemani oleh narasumber yang bertindak sebagai pendamping atau fasilitator yang menyampaikan materi secara aktif dan visual melalui pengamatan langsung.

Metode CBIA dipilih sebagai model edukasi pemberdayaan agar masyarakat lebih terampil dalam memilih obat sehingga swamedikasi menjadi lebih efektif, aman, dan hemat biaya. Metode CBIA merupakan metode pendidikan yang bertujuan untuk menumbuhkan sikap kritis peserta sehingga timbul motivasi atau keinginan untuk menemukan dan untuk melakukan sesuatu, baik berupa motivasi dari luar atau keluarga maupun motivasi dari dalam diri peserta. Fasilitator hanya berfungsi sebagai motivator agar minat dan potensi peserta dapat berkembang. Tujuan CBIA adalah terbentuknya kemampuan untuk menggali sumber informasi dan meningkatkan kebiasaan berpikir secara kreatif dan kritis sehingga mampu memecahkan masalah yang didasarkan pada proses belajar mandiri (self-learning). Berdasarkan penelitian yang telah dilakukan, diketahui bahwa metode CBIA terbukti lebih efektif untuk meningkatkan pengetahuan peserta perihal pengobatan secara mandiri $(4,9 \pm 0,3$ menjadi $8,3 \pm 0,2 ; p<0,001)$ (Suryawati, 2012). Pengetahuan peserta yang menghadiri seminar besar hanya mengalami peningkatan dari 4,5 $\pm 0,6$ menjadi $6,4 \pm 0,3$ ( $\mathrm{p} \leq 0,05)$, dan pada kelompok kontrol hampir tidak mengalami peningkatan, yaitu dari 4,2 $\pm 0,4$ menjadi $4,8 \pm 0,3$ (Suryawati, 2012). Selain dari segi metode, keberhasilan kegiatan juga didukung oleh antusiasme peserta yang tinggi dan karakteristik peserta yang sebagian besar berpendidikan setara atau lebih tinggi dari SMA. Sebuah studi menyebutkan bahwa interaksi antara strategi atau metode penyuluhan dengan tingkat pendidikan peserta memiliki hubungan yang positif dalam proses pembelajaran untuk mewujudkan sikap perhatian dan minat ibu rumah tangga (Pratomo, 2015).

\section{KESIMPULAN}

Swamedikasi merupakan perilaku yang tidak berbahaya apabila dilakukan dengan benar. Gerakan keluarga sadar obat digagas sebagai langkah untuk meluruskan banyaknya kesalahan persepsi terkait penggunaan obat secara mandiri yang terjadi di masyarakat. Dua pokok kegiatan dalam kegiatan ini adalah pemberian materi dan pendampingan keluarga. Pemberian materi berupa pemaparan materi yang berkaitan dengan penggolongan obat, penggunaan obat, penyimpanan obat, dan pembuangan obat yang rusak atau dikenal dengan jargon Dagusibu (Dapat, Gunakan, Simpan, dan Buang). Pemaparan diselingi dengan simulasi langsung tentang teknik pemakaian obatobatan yang biasa dilakukan di rumah. Metode yang digunakan dalam pemberian materi adalah metode pembelajaran aktif. Metode tersebut dinilai mampu meningkatkan kemampuan untuk menggali sumber informasi dan meningkatkan kebiasaan berpikir kreatif dan kritis dalam swamedikasi. Peningkatan kemampuan tersebut terbukti dengan peningkatan nilai post-test yang bermakna dibandingkan dengan nilai pre-test $(p<0,05)$. Kegiatan pengabdian ini perlu dilakukan berkala dengan melibatkan sasaran yang lebih luas sebagai upaya untuk meningkatkan peran masyarakat dalam mewujudkan kesehatan nasional.

\section{UCAPAN TERIMA KASIH}

Kami menyampaikan terima kasih kepada Dekan Fakultas Kedokteran dan Ilmu Kesehatan, Universitas Warmadewa atas hibah yang telah diberikan sehingga kegiatan pengabdian ini dapat diselenggarakan dengan lancar. Terima kasih juga kami sampaikan kepada Ibu Sukasih selaku mitra atas kerja sama dalam menyukseskan kegiatan ini dan seluruh pihak yang telah membantu.

\section{DAFTAR PUSTAKA}

Aswad, P.A., Kharisma, Y., Andriane, Y., Respati, T., \& Nurhayati, E. (2019). Pengetahuan dan Perilaku Swamedikasi oleh Ibu-Ibu di Kelurahan Tamansari Kota Bandung. Jurnal Integrasi Kesehatan \& Sains, 1(2): 107-113.

Antari, N.P.U \& Putra, A.S. (2014). Tingkat Pengetahuan tentang Penanganan Obat dalam Swamedikasi dan Pengaruhnya terhadap Kebiasaan Menggunakan Obat pada Respoden di Apotek Gunung Sari [Skripsi]. Denpasar: Akademi Farmasi Saraswati.

BKKBN. (2011). Profil Hasil Pendataan Keluarga Tahun 2011. Jakarta: Badan Kependudukan dan Keluarga Berencana Nasional.

Badan Pusat Statistik [BPS]. (2018). Sosial dan Kependudukan Kota Denpasar. Diakses dari https://denpasarkota.bps.go.id/?pages=4

Farmakologi dan Farmasi FKIK Unwar. (2018). Panduan Praktikum Bagian Farmakologi dan Farmasi. Denpasar: Fakultas Kedokteran dan Ilmu Kesehatan Universitas Warmadewa.

Galato, D., Galafassi, L.M., Alano, G.M., \& Trauthman, S.C. (2009). Responsible Self-Medication: Review of the Process of Pharmaceutical Attendance. Brazillian Journal of Pharmaceutical Science, 45(4): 625-633.

Handayani, R. (2018). Peningkatan Pengetahuan IbuIbu Rumah Tangga dalam Perilaku Pengobatan Sendiri untuk Penatalaksanaan Demam dengan Metode Cara Belajar Ibu Aktif. Borneo Journal of Pharmacy, 1(1): 27-30.

Kemenkes RI. (1993). Peraturan Menteri Kesehatan Nomor 919/Menkes/Per/X/1993 tentang Kriteria 
Obat yang Dapat Diserahkan Tanpa Resep. Jakarta: Kementerian Kesehatan RI.

Kemenkes RI. (2013). Riset Kesehatan Dasar (RISKESDAS). Jakarta: Balitbang Kemenkes RI.

Noerdianingsih, E. (2014). Peningkatan Pengetahuan dan Perilaku Siswa SMA di Kota Metro dalam Swamedikasi Common Cold Dengan Metode Cara Belajar Insan Aktif (CBIA) [Tesis]. Yogyakarta: Universitas Gajah Mada.

Pratomo, S. (2015). Pengaruh Strategi Penyuluhan dan Tingkat Pendidikan terhadap Kepedulian Kesehatan Lingkungan. Metode Didaktik, 9(2): 34- 48 .

Permatananda, P.A.N.K., Kristin, E., Endharti, D., Pinzon, R.T., \& Sumada, I.K. (2018). Adverse Event of Antiepileptic Drugs: A Cross Sectional Study. MATEC Web of Conference 19707004.

Silva, B.P., Hussain, F.H., Ginige, G., Kulathunge, A., Kannangara, H., Gonawardane, S., \& Gamage, M. (2017). Self-medication Practices and Misuse of Medicine among Mothers of Young Children Attending a Teaching Hospital in Sri Lanka. Sri Lanka Journal of Child Health, 46(2): 122-127.

Suryawati, S. (2012). Meningkatkan Keterampilan Memilih Obat dengan Metode CBIA. Yogyakarta:Pusat Studi Farmakologi Klinik dan Kebijakan Obat UGM.
Volmer, D., Lilja, J., \& Hamilton, D. (2007). How Well Informed are Pharmacy Customers in Estonia about Minor Illnesses and Over-the-counter Medicines. Medicina (Kaunas), 43(1): 70-78.

Whittington, Z., Cantrill, J., Hassel, K., Bates, F., \& Noyce, P. (2001). Community Pharmacy Management of Minor Conditions: the "At the Chemist" Scheme. Pharm J., 266: $\quad$ 425-428.

Widayati, A., Suryawati, S., Crespigny, C., \& Hiller, J.E. (2008). Identifying Key Beliefs of Self Medication with Antibiotics in Yogyakarta City Indonesia. Diakses dari http://www.inrud.org

Wisudarma, I.G.A., Kaler, S., \& Subramaniam, A. (2015). Kemauan Masyarakat Pengguna Jaminan Kesehatan Bali Mandara Mengikuti Jaminan Kesehatan Nasional di Wilayah Kerja Puskesmas Petang II. Jurnal Skala Husada, 12(1): 32-38.

World Health Organization [WHO]. (1998). The Role of the Pharmacist in Self-care and Selfmedication. Hangue: World Health Organization, p. 17.

Zoraida, A.R. (2012). Peningkatan Ketrampilan Mencari Informasi pada Kemasan dan Lembar Sisipan Obat Bebas dan Bebas Terbatas dengan Metode Cara Belajar Ibu Aktif (CBIA)[Skripsi]. Yogyakarta: Universitas Gadjah Mada 